Ann. rheum. Dis. (1962), 21, 176.

\title{
CLINICAL COMPARISON OF THE NEWER ANTI-INFLAMMATORY CORTICOSTEROIDS*
}

\author{
BY
}

\author{
EDWARD W. BOLAND \\ Los Angeles, California, U.S.A.
}

The discovery by Hench, Kendall, Slocumb, and Polley (1950) that cortisone has the capacity to reverse the inflammatory reactions of rheumatoid arthritis stimulated great research activity in many disciplines of medicine. Biochemists, physiologists, and physicians, gifted with imagination and skilled in basic research, have contributed a vast body of knowledge about the mechanisms of adrenocortical secretion. The rates, cycles, and pathways of their biosynthesis have been explored; and their disposition and metabolic fates are now known. Much valuable information has also been acquired about the influence of adrenocortical steroids on carbohydrate, protein, and electrolyte metabolism, their effects on the processes of inflammation and immune reactions, their influence on the response of mesenchymal tissues, and their interrelation with the function of other endocrine glands. Simultaneously, resourceful physicians of many lands have been making practical application of corticosteroid compounds as treatment agents in a variety of disease states, including several rheumatic disorders, and have been critically appraising their merits, deficiencies, and hazards.

Investigators have been especially active in the chemical development, animal testing, and clinical assessment of chemically modified derivatives of cortisone and hydrocortisone. Research has been channelled in this direction with the aim of determining how alterations in formulae influence biological function, and, if possible, of devising compounds with greater therapeutic efficiency than the natural hormones. Since cortisone and hydrocortisone have serious limitations as treatment agents for rheumatoid arthritis and other chronic

* Address delivered at the Royal Society of Medicine, London, on September 12, 1961. From the Department of Medicine of the University of Southern California School of Medicine and of St. Vincent's Hospital, Los Angeles, California, U.S.A. diseases responsive to steroids, the need for drugg with higher therapeutic indices has long been evident. Among the deficiencies inherent in the natural hormones are their suppressive rather than curative effect, the ephemeral nature of their benefits, their failure to halt the natural progression of rheue matoid arthritis even while adequate degrees of improvement and functional rehabilitation are being maintained, and their inhibiting effect or endogenous adrenocortical function.

Moreover, their usefulness, even as suppressiv@ agents, is severely limited by their multiple physio logical properties. In addition to their anti inflammatory effect, they have many other actionso some of which produce unwanted signs of hormonat excess. The intrusion of these often prohibits the administration of doses of sufficient strength to maintain satisfactory improvement. The commo undesirable reactions are now well known. The include heightened appetite coupled with excessive weight gain and abnormal deposits of adipose tissue; disturbances of electrolyte metabolism 3 particularly sodium and water retention and potase sium loss, increased capillary fragility, cutaneous ecchymoses, thinning of the skin, striae, acne, an hypertrichiasis in women, negative calcium balance and osteoporosis; retardation of fibrosis and delaye $\mathbb{P}$ healing; elevation of blood pressure; nervous irritability; masking of infections; and other effects And, in the course of treatment, unwanted physioo logical actions may promote such complications as peptic ulcer, pathological fractures, phlebitis thrombo-embolic phenomena, emotional psychotie? disturbances, necrotizing vasculitis, and peripherato neuropathy - or they may aggravate certain diseas $\overrightarrow{\bar{E}}$ states, such as arterial hypertension, peptic ulcer diabetes, osteoporosis, and tuberculosis, that ma范 co-exist with rheumatoid arthritis.

Were it possible to modify the chemical structures 
of the basic steroids in such a way as to eliminate or attenuate those biological functions that promote objectionable "side-effects" and complications, while retaining their potent anti-inflammatory actionthat is to split off the desired from the undesired properties-then suppressive drugs with greater therapeutic efficiency could be created.

\section{Development of Chemically-Modified Corticosteroid COMPOUNDS}

That seemingly minor variations in the molecular composition of adrenocortical steroids might be reflected by quantitative differences in their biological properties was suggested by studies which compared the effects of cortisone and hydrocortisone in laboratory animals. In 1945, four years before the anti-inflammatory effect of cortisone was discovered, hydrocortisone, which differs from cortisone in only one structural detail-namely, the presence of a hydroxyl radical rather than a ketone group at the eleventh carbon position of the phenanthrene ring-was found to have greater physiological activity. Results of muscle-work tests, liver glycogen assays, and observations of the regressive changes produced in the thymus and adrenal glands indicated that hydrocortisone has twice the potency of cortisone (Ingle and Kuizenga, 1945; Pabst, Sheppard, and Kuizenga, 1947). Moreover, twice as much cortisone as hydrocortisone was required to promote equivalent eosinopenic responses (Thorn, 1950). Subsequently hydrocortisone was shown by us (Boland, 1952; Boland and Headley, 1952), and by Hench and Ward (1954) to have greater antirheumatic activity than cortisone. Studies that compared the milligram doses required for the maintenance of equivalent control of rheumatoid manifestations revealed that hydrocortisone was about 30 per cent. more potent. As long as 10 years ago, clinical investigators reported that, with equally effective doses, hydrocortisone is less likely than cortisone to produce mental excitation and oedema. This observation suggested to researchers that subtle changes in chemical composition might selectively influence biological properties other than the anti-inflammatory.

The first indisputable evidence that the functions of the natural corticoids could be altered selectively was supplied by Fried and Sabo $(1953,1954)$. These investigators observed that the addition of halogen atoms at the ninth carbon position of hydrocortisone caused enhancement of several of its biological properties. Most significant was the fact that the potentiation did not apply with equal intensity to all metabolic functions and that the biological characters of the artificial compounds differed in accordance with which halogen-i.e. chlorine, fluorine, iodine, or bromine-was substituted. For example, 9-alpha fluorohydrocortisone, or fludrocortisone as it was later named, proved to be ten to fifteen times more powerful than the parent hormone in promoting glycogen deposition and suppressing anti-inflammatory responses in the rat; and it was fifty times more potent in retaining salt (Borman and Singer, 1954; Borman, Singer, and Numerof, 1954).

Among rheumatoid patients, the antirheumatic strength of fludrocortisone was found to be ten times greater than that of hydrocortisone; and it was also ten times more potent in eosinopenic, ACTH suppressing, and nitrogen wasting effects (Boland and Headley, 1954). Our own clinical experiences with the compound in 1954 led to considerable early enthusiasm, but this was soon dampened when it became obvious that the sodiumretaining and potassium-losing properties of the compound were enhanced to a much greater degree than its anti-inflammatory activity (Boland, 1955). After a few days of administration, pronounced oedema developed in most of the patients; and this precluded its practical application systemically as an anti-inflammatory drug. Nonetheless, observations with 9-alpha fluorohydrocortisone led to the inescapable conclusion that the mineralocorticoid, glucocorticoid, nitrogen anti-anabolic, and antiphlogistic activities of steroids could be altered profoundly and perhaps selectively by modifying their formulae.

Since 1953, a multitude of synthetic compounds have been devised by chemists, many of which are yet untested, even in animals. Of those that have received trial, many have demonstrated differences in anti-inflammatory potency and some have exhibited amplification or attenuation of one or another biological property. Steroids of therapeutic interest have resulted from the following chemical changes in formulae of hydrocortisone and cortisone: fluorination at C-9 and at C-6; dehydrogenation at C-1-C-2 and at C-6-C-7; methylation at C-2, at $\mathrm{C}-6$, at $\mathrm{C}-16$, and at $\mathrm{C}-21$; hydroxylation at $\mathrm{C}-16$; and desoxygenation at $\mathrm{C}-21$. When introduced singly, each of these modifications alters one or several biological functions of the parent compound. When introduced in combination, of two, three, or even more, extremely complex analogues are produced, some of which exhibit unique, and even bizarre, properties. Laboratory and clinical studies conducted with such compounds during the past 7 years have yielded useful, though still fragmentary, information regarding the structure-function relationship of steroids.

During the past 10 years, our group has assessed, 
on either long-term or short-term basis, the antirheumatic effects of 33 different analogues (Boland, $1961 \mathrm{a}$, b). Some of these, together with their antirheumatic potencies as determined among rheumatoid patients, are listed in the Table.

\section{TABLF}

ANTIRHEUMATIC POTENCIES OF CERTAIN CHEMICALLY MODIFIED ADRENOCORTICAL STEROID COMPOUNDS

\begin{tabular}{|c|c|c|}
\hline \multirow{2}{*}{ Compound } & \multicolumn{2}{|c|}{$\begin{array}{l}\text { Potency Times that of } \\
\text { Prednisolone (taking } \\
\text { Prednisolone as } 1 \cdot 0 \text { ) }\end{array}$} \\
\hline & $\begin{array}{c}\text { Range } \\
\text { (individual } \\
\text { cases) }\end{array}$ & Average \\
\hline * Prednisolone and Prednisone & $\cdots$ & $1 \cdot 0$ \\
\hline 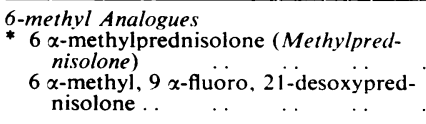 & $\begin{array}{l}\ldots \quad 1 \cdot 0-2 \cdot 0 \\
\ldots \quad 0 \cdot 25-0 \cdot 5\end{array}$ & $\begin{array}{l}1 \cdot 15 \\
0 \cdot 3\end{array}$ \\
\hline 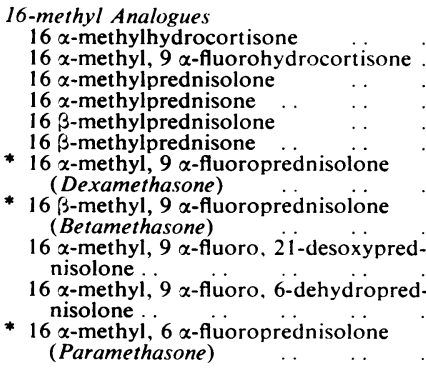 & $\begin{array}{l}\ldots \quad 0 \cdot 3-1 \cdot 0 \\
\ldots \quad 2 \cdot 5-4 \cdot 2 \\
\ldots \quad 1 \cdot 0-1 \cdot 7 \\
\ldots \quad 1 \cdot 0-1 \cdot 3 \\
\ldots \quad 1 \cdot 0-1 \cdot 5 \\
\ldots \quad 1 \cdot 0-1 \cdot 2 \\
\ldots \quad 5 \cdot 0-10 \cdot 0 \\
\ldots \quad 6 \cdot 0-8 \cdot 0 \\
\ldots \quad 1 \cdot 0-1 \cdot 6 \\
\ldots \quad 5 \cdot 0-10 \cdot 0 \\
\ldots \quad 2 \cdot 5-3 \cdot 5\end{array}$ & $\begin{array}{l}0 \cdot 65 \\
3 \cdot 2 \\
1 \cdot 3 \\
1 \cdot 1 \\
1 \cdot 25 \\
1 \cdot 0 \\
7 \cdot 1 \\
6 \cdot 8 \\
1 \cdot 25 \\
6 \cdot 8 \\
2 \cdot 8\end{array}$ \\
\hline $\begin{array}{l}\text { 16-hydroxy Analogues } \\
16 \alpha \text {-hydroxyprednisolone } \\
16 \alpha \text {-hydroxy, } 9 \alpha \text {-fluoroprednisolone } \\
\text { (Triamcinolone) } . \\
16 \alpha \text {-hydroxy, } 6 \alpha \text {-fluoro, } 9 \alpha \text {-fluoro- } \\
\text { prednisolone } . \\
16 \alpha \text {-hydroxy, } 6 \alpha \text {-fluoroprednisolone }\end{array}$ & $\begin{array}{l}\ldots 0 \cdot 25-0 \cdot 75 \\
\ldots 1 \cdot 0-1 \cdot 5 \\
\ldots \quad 1 \cdot 8-2 \cdot 5 \\
\ldots 0 \cdot 3-0.6\end{array}$ & $\begin{array}{l}0 \cdot 5 \\
1 \cdot 15 \\
2 \cdot 3 \\
0 \cdot 5\end{array}$ \\
\hline 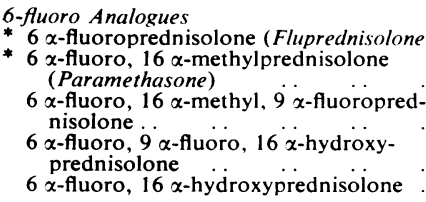 & $\begin{array}{l}\text { e) } 2 \cdot 3-4 \cdot 2 \\
\ldots \quad 2 \cdot 5-3 \cdot 5 \\
\ldots \quad 5 \cdot 0-9 \cdot 3 \\
\ldots \quad 1 \cdot 8-2 \cdot 5 \\
\ldots \quad 0 \cdot 3-0 \cdot 6\end{array}$ & $\begin{array}{l}2 \cdot 6 \\
2 \cdot 8 \\
7 \cdot 8 \\
2 \cdot 3 \\
0 \cdot 5\end{array}$ \\
\hline $\begin{array}{l}\text { Miscellaneous Analogues } \\
9 \alpha \text {-fluoro, } 21 \text {-desoxycortisone } \ldots \\
9 \alpha \text {-fluoroprednisolone } \\
9 \alpha \text {-fluoro, } 21 \text {-methylprednisolone } \\
6 \alpha \text {-fluoro, } 9 \alpha \text {-fluoro, } 21 \text {-methylpred- } \\
\text { nisolone .. . . . . . . . }\end{array}$ & $\begin{array}{l}\ldots \quad 0 \cdot 2-0 \cdot 5 \\
\ldots \quad 3 \cdot 0-5 \cdot 0 \\
\ldots \quad 1 \cdot 0-1 \cdot 67 \\
\ldots \quad 1 \cdot 0-1 \cdot 75\end{array}$ & $\begin{array}{l}0 \cdot 3 \\
4 \cdot 3 \\
1 \cdot 2 \\
1 \cdot 3\end{array}$ \\
\hline
\end{tabular}

* Compounds described in this paper.

Eight of the compounds have been introduced commercially as therapeutic agents for rheumatoid arthritis and other responsive disease states; these are prednisone, prednisolone, methylprednisolone, triamcinolone, dexamethasone, betamethasone, fluprednisolone, and paramethasone. We have carried out long-term treatment studies with each of them and in this communication an attempt is made tक summarize in general terms their relative merits an disadvantages.

The chemical formulae of the original cortison and hydrocortisone and the eight therapeutic derivatives are shown in the Figure (opposite).

\section{Prednisone and Prednisolone}

Herzog, Nobile, Tolksdorf, Charney, Hershberg Perlman, and Pechet, 1955) introduced a doubleू bond at the first and second carbon position of cortisone and hydrocortisone, thereby producing their delta-1 analogues, prednisone and prednisolone-Dehydrogenation at this position was found tô enhance anti-inflammatory potency and glycogerg deposition without causing a corresponding increase in electrolyte activity (Bunim, Pechet, and Bolletc 1955). Each synthetic analogue that has been mar? keted since 1955 has contained this chemical altera tion. Prednisone and prednisolone possess similaro adrenocortical activity. As measured by eosinopenic ${ }^{\mathfrak{N}}$ response, liver glycogen deposition, and thymus involution in adrenalectomized mice, the biologicas activity of prednisone and prednisolone has been shown to be three to four times greater than that of hydrocortisone.

An attempt will now be made to review briefly $\overrightarrow{0}$ our clinical evaluations of prednisolone and pred 3 nisone, based on observations made during long? term treatment studies of more than 400 patients with rheumatoid arthritis treated with the comw pounds over a 5-year period. The antirheumatio potencies of prednisone and prednisolone pers milligram are, on an average, approximately four times greater than those of hydrocortisone-the range in our cases being from $2 \cdot 4: 1$ to $5 \cdot 3: 1$ (Boland, 1956). Accordingly, the doses requireof are smaller than with hydrocortisone. In our practice, the upper limits for maintenance doses: have been 10 to $12.5 \mathrm{mg}$. a day for severe cases $N$ 7.5 to $10 \mathrm{mg}$. for moderately severe cases, and 5 to $7.5 \mathrm{mg}$. for moderate cases. Dosage com N parison studies of 22 patients revealed that pred $\omega$ nisone and prednisolone were approximately equa in milligram potency; and our subsequent experience은 has justified the impression that in equal doses the two congeners promote about the same initia ${ }^{p}$ suppression, maintenance of improvement, and adverse reactions.

Among patients not previously treated with steroids, the pattern of improvement resulting from suppressive doses of comparable antirheumatic strength is much the same with prednisone ando 
<smiles>O=C1C=C2CCC3C(C(O)CC4(C(=O)CO)C(CO)CCC34)C2CC1</smiles>

HYDROCORTISONE<smiles>O=C1C=C2CCC3C2C(=O)CC2(CC1)C3CCC2(O)C(=O)CO</smiles>

CORTISONE<smiles>O=C1C=C2CCC3C2C(O)CC2(CCO1)C3CCC2(O)C(=O)CO</smiles>

PREDNISOLONE

( $\Delta^{\prime}$-hydrocortisone)

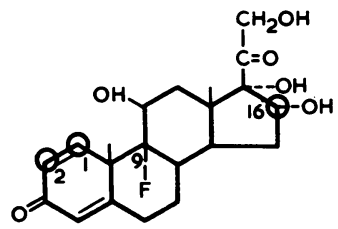

TRIAMCINOLONE

(16a-hydroxy, 9a-fluoroprednisolone)<smiles>O=C1C=C2CCC3C2C(=O)CC2(CC1)C3CCC2(O)C(O)CO</smiles>

PREDNISONE

( $\Delta^{\prime}$-cortisone)

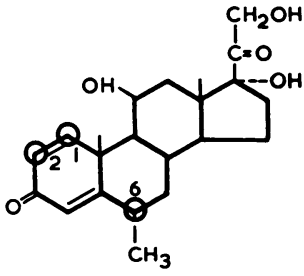

METHYL PREDNISOLONE

(6a-methylprednisolone) 
prednisolone as with hydrocortisone and cortisone. Statistical results of the improvement status among our patients after the first few months of treatment were similar with delta-1 analogues and hydrocortisone, but the results of long-term therapy were significantly better with the analogues. As with the older steroids, the number of patients showing adequate response declined as treatment was continued over the months, and overall results varied inversely with disease severity and duration. After prednisone or prednisolone had been administered continuously for one year, 55 per cent. of the patients retained satisfactory degrees of control.

Our observations, as well as those of others, indicate that prednisone and prednisolone are capable of maintaining satisfactory response among patients who are amenable to hydrocortisone therapy. In one of our early studies, medication was changed to one of the analogues in 39 patients who at the time were responding well to hydrocortisone. At the end of one year, 35 of them had retained adequate improvement. Deterioration in the remaining four patients, we believed, could be attributed to the development of steroid resistance from prolonged therapy rather than to refractoriness to prednisone or prednisolone per se.

Among seventy patients, we attempted to determine whether prednisone and prednisolone were capable of improving the status after satisfactory control with hydrocortisone had been lost. This group was a stubborn one and for the most part consisted of patients with more severe disease states whose conditions had regressed after having taken hydrocortisone in relatively large amounts (average $46 \mathrm{mg}$. per day) for long periods (average 19 months). In most instances, the dosages for individual patients were considered maximal with respect to adverse effects or prudency. Nearly one-half of the patients recovered and maintained their previous improvement after transfer to prednisone or prednisolone, although the dosages used were slightly larger in terms of antirheumatic strength. As prednisone or prednisolone therapy was continued, and the period of steroid administration was further prolonged, improvement again waned in certain patients; but in 34 per cent. of this recalcitrant group management remained successful for more than 2 years. The acquisition of higher levels of improvement with the analogues could be attributed in some patients, but not all, to the fact that an absence of salt and water retention permitted the employment of more effective doses.

An important question to which we sought an answer is how prednisone and prednisolone differ from hydrocortisone in their proclivity for undesir- able reactions. Observations made among $10 \overline{9}$. patients, whose medication was transferred directl淓 from hydrocortisone to the analogues, allowed comparisons to be made with respect to the incidence and character of hormonal side-effects. Fou震 general deductions were made:

(1) The total incidence of side-effects is nog lowered when prednisone or prednisolone is substituted for hydrocortisone in smalle? but equally potent antirheumatic doses; $\vec{\omega}$

(2) The number of side-effects is increase when the analogues are employed if dosages that exceed equivalently poten doses of hydrocortisone;

(3) Prednisone and prednisolone differ from hydrocortisone in their tendency to promot? certain individual side-effects;

(4) The occurrence of undesirable physiologicat effects is contingent, as with hydrocortisone on individual patient susceptibility, the sizes of the dose employed, the duration dP administration, and sex.

Prednisone and prednisolone differ from hydro cortisone in their proclivity for individual unwanteg effects. After transfer of medication from hydro $\mathbb{B}$ cortisone, the incidence of salt and water retention and raised blood pressure are greatly reduceds Conversely, digestive complaints, peptic ulcers, vasomotor symptoms, and cutaneous ecchymoses develop more frequently (Boland, 1957, 1959) Other undesirable reactions, such as facial mooning fat pads, nervous excitation, hypertrichosis, acne skin tabs, disturbances in glucose tolerance, and osteoporosis, seem to appear with similar frequenç when comparable antirheumatic doses are pres cribed. It has been shown that the incidences of digestive complaints and of roentgenographically identified ulcers are substantially reduced wheo. non-absorbable antacids are taken with each dosee of the drugs, and that the incidences are then no greater than during hydrocortisone administration (Boland, 1958a; Boland and Headley, 1958). N

Like most investigators, we prefer prednisone of prednisolone to hydrocortisone and cortisone fom rheumatoid patients requiring steroid therapy. Th. reasons for this choice are their lower tendency t\& produce salt and water retention and potassiump loss, their ability to restore improvement in a sign? ficant percentage of patients after improvement from hydrocortisone has deteriorated, and the bettef statistical results on long-term administration. seems justified to conclude, then, that the theras 
peutic indices of prednisone and prednisolone are higher than those of cortisone and hydrocortisone.

\section{Methylprednisolone}

Hogg, Lincoln, Jackson and Schneider (1955) and Spero, Thompson, Magerlein, Hanze, Murray, Sebek, and Hogg (1956) synthesized and tested biologically a number of steroids with a methyl group at the sixth carbon position. Their interest in compounds that contained such a modification was prompted by knowledge that the sixth carbon position was important in the process of metabolic oxidation. It was thought that the presence of a substituent at C-6 might slow down the enzymatic reduction which causes the inactivation of corticosteroids and thus increase the intensity and/or duration of their action. Biological experiments in animals disclosed that, in contrast to methylation at the second carbon position, the introduction of a methyl group at C-6 tended to potentiate the antiinflammatory property without increasing electrolyte activity. The liver glycogen depositing activity of methylprednisolone was found to be sixteen times greater than that of hydrocortisone. As measured by the granuloma pouch technique, its anti-inflammatory activity was 5.5 times greater than that of hydrocortisone and twice that of prednisolone. These findings suggested that methylprednisolone might possess a partial dissociation of properties-one that might be interesting and useful clinically.

During 1956 and 1957, we collaborated with Dr. Grant Liddle of Vanderbilt University in the study of the metabolic and antirheumatic effects of methylprednisolone (Boland and Liddle, 1957). Dr. Liddle's metabolic studies indicated that in human subjects the sodium-retaining and potassiumlosing activities of methylprednisolone were slightly, but not conclusively, less than those of prednisolone. The compound was found to be at least as powerful as prednisolone as a nitrogen-wasting agent, and it produced the same degree of pituitary-adrenal functional inhibition when it was given in equal milligram doses. Furthermore, the reductions in the number of eosinophils which occurred during administration of the compound did not differ significantly from those noted with equal milligram amounts of prednisolone.

From clinical observations in 41 rheumatoid patients we were permitted to make certain deductions. Direct comparisons of dosages required to uphold similar degrees of clinical improvement were made in nineteen patients, and these revealed that methylprednisolone and prednisolone did not differ much in antirheumatic strength; on an average, methylprednisolone was estimated to be about 20 per cent. more potent per milligram. The character and degree of improvement that resulted from methylprednisolone employed as initial therapy were identical with those which would be anticipated from prednisolone given in somewhat larger milligram amounts. Among patients being maintained on either drug, transfer of medication from one to the other did not interfere significantly with the state of improvement.

The type, incidence, and degree of adverse reactions were essentially the same as from prednisolone, although its proclivity to salt retention was thought to be less. Our studies did not permit true comparisons of incidence of peptic ulcers and osteoporosis resulting from the use of the two compounds -and, unfortunately, such data have not been forthcoming from other sources.

From these initial observations and from a subsequent larger clinical experience, the conclusion was reached that methylprednisolone is a satisfactory antirheumatic agent; but that in comparison with prednisolone it does not exhibit clear-cut advantages or disadvantages. Since both compounds promote similar responses in previously untreated patients, uphold clinical improvement equally well on long-term administration, and provoke adverse effects which, for the most part, are similar in kind and frequency, it would appear that their therapeutic indices are about equal. In the United States, methylprednisolone is, at the present time, used more widely than any other steroid. This may be attributed to the fact that physicians and patients alike seem to have a penchant for new drugs, that it has been successfully promoted by its manufacturer, and that it produces no peculiar "new bad effects" of its own.

\section{Triamcinolone}

Bernstein, Lenhard, Allen, Heller, Littell, Stolar, Feldman and Blank (1956) created several compounds containing an hydroxyl radical at the C-16 position. This substitution uniformly lessens glucocorticoid potency and drastically reduces mineralocorticoid activity. The presence of an hydroxyl group at C-16 practically eliminates the severe sodium retention which results from 9-alpha fluorination and allows compounds containing this substituent to be prescribed systemically.

Triamcinolone is a complex steroid which differs from prednisolone by the addition of an hydroxyl radical at C-16 and a fluorine atom at the C-9 position (Figure). Biological assays reveal that its glyco- 
gen deposition activity is thirteen times greater than that of hydrocortisone-and that its anti-inflammatory strength, as measured by granuloma formation, is four times greater. Sodium retention is not provoked by the drug; but, on the contrary, marked diuresis and sodium removal are produced in adrenalectomized rats loaded with salt, and even in normal rats and dogs. Balance studies in human subjects indicate that the agent produces slight losses of nitrogen, calcium, and phosphorus with dosages in therapeutic range, and that sodium excretion often occurs during the first few days of administration.

From the experiences of Freyberg, Berntsen, and Hellman (1958), and as a result of our own longterm observations of 62 rheumatoid subjects (Boland, 1960), a comparison of the effects of triamcinolone and prednisolone may be summarized as follows:

On a weight for weight basis, the antirheumatic potency of triamcinolone is somewhat greater (about 20 per cent. on average) than prednisolone, and is about equal to methylprednisolone. At dosage levels up to $12 \mathrm{mg}$. a day, the compound does not cause sodium retention-in fact, it may induce sodium and water diuresis.

The improvement that results from triamcinolone as initial treatment is similar to that noted from other steroid compounds possessing powerful antirheumatic activity. In our experience, however, the percentage of patients that are maintained satisfactorily for long periods of time is distinctly smaller than with prednisolone and methylprednisolone. This is due principally to the fact that troublesome side-effects peculiar to the drug frequently intrude during the course of treatment and make the transfer of medication to another steroid necessary or prudent. Actually it was found advisable to discontinue triamcinolone in approximately 25 per cent. of our patients who received the drug as initial treatment and in over 30 per cent. of those whose medication was transferred from prednisolone.

When comparable antirheumatic dosages of prednisolone and triamcinolone are employed, there is a considerable difference in the incidence and degree of individual unwanted hormonal reactions: Triamcinolone, as already indicated, has less tendency than any other commercially available steroid to cause salt and water retention. Oedema, of even a slight degree, is rarely seen-and the drug is not prone to produce or aggravate arterial hypertension. It has less tendency than other steroid preparations to appetite stimulation, and it frequently causes anorexia and weight loss. It seems to have about the same tendency as prednisolone to produce such objectionable reactions as menta ${ }^{9}$. irritability, hirsutism, acne, striae, vasomoto $\overrightarrow{5}$ symptoms, glycosuria, and dyspepsia. Although conclusive data are not available, the same is probably true for osteoporosis, peptic ulceration an its complications, and vasculitis. In our experience the incidence and severity of thinning and friability of the skin, increased fragility of the cutaneous capillaries, and ecchymotic lesions are greater witb triamcinolone and dexamethasone - both of which contain a $9 \alpha$-fluoro substituent-than with othe $\vec{g}$ steroids.

Among the unique unwanted effects of triame cinolone are anorexia, weight loss-sometimes witi notable wasting of subcutaneous and muscle tissue $-\dot{+}$ muscle weakness, leg cramps, nausea, cutaneous erythema, dryness and burning sensations, generalo ized fatigue, and dizziness. The occurrence rates for some of these have been substantial: anorexia in 10 per cent., muscle weakness in 16 per cent., anc pronounced weight loss in 18 per cent. Thes peculiar effects have been troublesome enough t $\vec{\Phi}$ discourage its routine use for rheumatoid patient\$s requiring steroid therapy. In our opinion, the drug may be employed to best advantage as a "specia零 purpose" steroid. It should be reserved for selecte $\$$ situations, such as when salt and water retention develops from other steroids or from cardia decompensation, or when excessive appetite an\& weight gain are problems in management.

\section{Dexamethasone}

Arth, Johnston, Fried, Spooncer, Hoff, an $\bar{\Phi}$ Sarett (1958), Arth, Fried, Johnston, Hoff, Sarete Silber, Stoerk, and Winter (1958), and Oliveto (1959. independently synthesized a family of analogues containing, in common, a methyl grouping at C-16. 16-methylation, like 16-hydroxylation, markedlo reduces the salt-retaining property of 9-alphis fluorinated compounds, so allowing them to be usec. systemically. By contrast, however, 16-methylationt does not reduce anti-inflammatory potency but often increases it greatly (Silber, 1959). Altogethes we have studied eleven different 16-methylated compounds. In general, antirheumatic activit茨 has been decidedly enhanced by the presence of methyl group at C-16 if the compound also contain $\$$ a $9 \alpha$-fluoro component; but the potency has been only slightly increased if the fluoro substituent is absent.

Dexamethasone differs from prednisolone by the presence of a methyl grouping at the 16 alph position and of a fluorine atom at the 9 alphe position (Figure). Biological tests have demono 
strated that this analogue is one of the most powerful anti-inflammatory steroids yet devised. Its activity, as determined by thymus involution, is $140-200$ times greater than that of hydrocortisone; by granuloma inhibition, 200 times greater; and by glycogen deposition, twenty times greater. Sodium retention in animals is not provoked even at high dosage levels. Its influence on carbohydrate metabolism was found to be less than on anti-inflammatory activity - a finding that suggested a dissociation of properties which might be useful therapeutically, especially in patients with co-existing diabetes mellitus. Unfortunately, however, studies of its hyperglycaemic effects in man did not justify this hope. Frawley, Kistler, and Shelley (1959), and West, Johnson, Kyriakopoulos, Bahr, and Bloedow (1960) determined that the hyperglycaemic, as well as the eosinopenic and adrenal suppressive, potencies of dexamethasone parallel its anti-inflammatory strength.

Clinical evaluations with dexamethasone were conducted independently by Boland $(1958 \mathrm{~b}, \mathrm{c})$ and by Bunim, Black, Lutwak, Peterson, and Whedon (1958), and the results were remarkably similar in most particulars. Our series embraced 110 patients who, during the time of analysis, had been treated for periods ranging from 12 to 24 months. Direct dosage comparison studies revealed that dexamethasone is about seven times more potent in antirheumatic activity than prednisolone on a weight for weight basis. Among individual patients there was a rather wide range of potency $(1: 5$ to $1: 10)$. However, in the majority of cases, it was $1: 6$ to $1: 8$. By calculation, then, dexamethasone is about 30 to 35 times more powerful than hydrocortisone. In our experience, the only steroid that has exhibited greater antirheumatic strength is a congener of dexamethasone that contains in addition a fluorine atom at C-6. The compound-16 $\alpha$-methyl, $9 \alpha$ fluoro, $6 \alpha$-fluoroprednisolone-is about eight times more potent than prednisolone.

Among patients not previously treated with steroids, dexamethasone prescribed in remarkably small initial doses, i.e. 0.5 to $2 \mathrm{mg}$. per day, promoted an immediate response and subsequent early improvement identical to that induced by other anti-inflammatory steroids given in much larger doses. Among our patients, the average maintenance dose was $1 \cdot 13 \mathrm{mg}$. a day.

A substantial number of patients who had ultimately become relatively refractory to prednisolone responded favourably to dexamethasone. In a recalcitrant group of 55 patients, who were suffering from severe or moderately severe disease and were poorly controlled by prednisolone, transfer of medication to dexamethasone resulted in the recovery and maintenance of adequate improvement by approximately one-third of them for periods of 6 to 9 months. The dosages used, in terms of antirheumatic strength, were slightly larger, on average, than the calculated equally potent doses. The improvement again deteriorated in many cases when treatment was continued for longer periods; but, at the end of 2 years, one-sixth of the group was still classified as adequately controlled.

An analysis of long-term treatment results for 92 of our patients revealed that the increased potency of dexamethasone was not accompanied by a lessening of undesirable effects. Actually, the overall incidence of unwanted reactions was greater than from comparably effective doses of prednisolone. The steroid had approximately the same proclivity to cause abnormal fat deposits in the face, supraclavicular, and cervicodorsal regions as well as hypertrichosis, acne, and nervous excitation. Peripheral oedema was noted uncommonly and, even then, was mild; its occurrence rate was 7 per cent., an incidence which was slightly lower than for prednisolone and greater than for triamcinolone. The steroid demonstrated little or no tendency to elevate blood pressure or to aggravate pre-existing hypertension.

On the debit side of the balance sheet, however, a number of unfavourable reactions were more common. Most objectionable of these were excessive appetite (in 21 per cent.), excessive weight gain (in 26 per cent.), excessive increase in abdominal girth (in 20 per cent.), and abdominal bloating and distension (in 16 per cent.). The frequency and severity of these reactions varied directly with the size of the maintenance dose; and an effort was made, therefore, not to exceed daily dosages of $1 \mathrm{mg}$. for females and $1.5 \mathrm{mg}$. for males. Even so, the symptoms were sufficiently troublesome to warrant change of medication to another steroid in one-third of the cases. Ecchymotic lesions were noted in 69 per cent. and thinning of the skin in 28 per cent. Except for triamcinolone, these cutaneous reactions developed more commonly and more intensively than from other steroids; and they worsened as dosage was raised and therapy was prolonged.

Digestive symptoms suggestive of peptic ulcer were uncommon, being experienced by only 2 per cent. of the patients. But, after 3 months of administration, routine gastro-intestinal $x$-ray studies disclosed that active peptic ulcers had developed in nine of 91 patients (10 per cent.). Eight of these nine patients had no digestive symptoms, and in six the lesions were gastric in location. This incidence was almost identical with that which we had found 
with prednisone or prednisolone among patients subjected to routine $x$ ray examinations (Boland, 1956).

Observations made during the past 3 years have led us to the conclusion that the general therapeutic efficiency of dexamethasone is distinctly less than that of prednisolone and methylprednisolone. We do not employ it as a general purpose steroid, but, instead, restrict its use to a very few special situations; as when refractoriness may prompt a change of medication to another steroid or when appetite stimulation and weight gain are desired and cannot be obtained with other compounds.

\section{Betamethasone}

Among the various 16-methylated steroids, synthesized in 1957 by Arth and others (1958a, b) and by Oliveto (1959), several contained the substitution at the beta rather than the alpha position. These analogues were of interest because they were the first ones with a beta-modification that demonstrated adrenocortical activity. During 1957 and 1958 , we studied three 16 beta-methyl compounds, including $16 \beta$-methyl, $9 \alpha$-fluoroprednisolone, later named betamethasone.

Data made available by the Merck Institute in 1957 and subsequent metabolic studies in man indicated that the biological characteristics of betamethasone paralleled those of dexamethasone. Its average antirheumatic potency, as determined in nine of our patients, proved to be 6.8 times greater than that of prednisolone, a figure which was comparable to that determined for dexamethasone. In 1957, and again more recently, we transferred patients from dexamethasone to betamethasone and back again, using identical milligram amounts. In general, the two congeners have proved to be interchangeable. From our observations of 32 rheumatoid patients given betamethasone for periods longer than 6 months, and from the larger experience of Kammerer (1961), it would appear that the compound possesses all of the deficiencies of dexamethasone and that its therapeutic index is about the same.

\section{Fluprednisolone}

Since the addition of a fluorine atom at C-9 caused striking changes in steroid activity and since modifications at C-6 were known to interfere with enzymatic reduction, it was logical for chemists to introduce fluorine atoms at C-6. In 1958, a series of compounds containing 6-fluoro substitutions was. synthesized (Hogg, Spero, Thompson, Magerlein;? Schneider, Peterson, Sebek, Murray, Babcock Pederson, and Campbell, 1958). In general, this modification intensifies anti-inflammatory, glycogen depositing, and eosinopenic activities, but not to such a degree as fluorination at C-9. In contrast to the effects of $9 \alpha$-fluorination, however, the addition of fluorine at C-6 does not disturb electro lyte metabolism.

The structure of fluprednisolone differs from $\overline{-}$ prednisolone only by the addition of a fluorine atonf at C-6. In animals its anti-inflammatory strength as gauged by granuloma inhibition, is approximatel eight times greater and its glycogen-depositing activity eighty times greater than that of hydro: cortisone. Results of nitrogen balance assays $\vec{\delta}$ ACTH suppression, eosinopenic, and hyperglyo caemic studies in man indicated that the compound was ten to twelve times more potent than hydro cortisone, or about three times more potent than prednisolone (Bowers and Ringold, 1958; Bowers ${ }_{2}^{\Phi}$ 1959).

During the past 3 years we have given the drug to 68 rheumatoid patients, 55 of whom have receiveo continuous administration for one year or longer Direct comparisons of dosage requirements in thirteen patients established that the antirheumatič potency of fluprednisolone is approximately $2 \cdot \frac{\mathrm{D}}{\mathrm{B}}$ times greater than that of prednisolone (Boland $\overrightarrow{\vec{F}}$ $1961 \mathrm{a}, \mathrm{b})$. Eleven patients not previously treated with steroids were given fluprednisolone in dailyo doses of 3 to $6 \mathrm{mg}$., depending upon disease activity? The immediate response was the same as for patients given other anti-inflammatory steroids in doses of̣ corresponding antirheumatic strength.

The medication of 44 patients was transferre from prednisolone to fluprednisolone. Contro of rheumatoid manifestations was still adequate on prednisolone in twenty patients, but the conditions of the remaining 24 had declined to inadequate levels $?$ In ten of these 24 resistant cases, satisfactory improve ment was regained after exchange of medication and was maintained thereafter for more than one year This indicated to us that there is a useful place for the drug in the management of patients who initiallye responded well to prednisolone, but later respond poorly to dosages within prudent therapeutic rangeo

Prednisolone and fluprednisolone promote adverse effects which are similar in most particulars. How ${ }^{+}$ ever, our observations indicate that fluprednisolone is less inclined to cause excessive weight gain and abnormal deposition of fat. This was evident in? the group of 44 patients in whom therapy was exchanged. After transfer to fluprednisolone, nine 
of sixteen patients with excessive weight gains sustained losses of from 5 to $16 \mathrm{lb}$.; and facial mooning and supraclavicular and/or cervicodorsal fat pads decreased or disappeared in ten of 24 patients presenting these changes. Several patients noted that appetite lessened following transfer. With maintenance doses ranging from $2 \cdot 25$ to $7 \mathrm{mg}$. a day (average $3.5 \mathrm{mg}$.), salt and water retention was not a problem. Our experience suggests that the therapeutic index of fluprednisolone is at least as great as, and probably greater than, that of prednisolone (Boland, 1960).

\section{Paramethasone}

A recent product of chemical manipulation is paramethasone (Edwards, Ringold, and Djerassi, 1960), which differs from fluprednisolone by the presence of a methyl grouping at C-16. Biological assays in animals suggested that paramethasone had an interesting skewing of properties. By the cotton-pellet granuloma test its anti-inflammatory strength was approximately fifty times that of hydrocortisone, and figures for its thymolytic activity were similar. Its glycogen deposition activity was found to be 150 times greater than that of hydrocortisone, and mineral assays in adrenalectomized rats without sodium chloride loading revealed that sodium was excreted rather than retained (Syntex Laboratories, personal communication). In man, paramethasone caused slight loss of sodium and chloride and little or no loss of potassium when doses of 6 to $15 \mathrm{mg}$. were given (Irwin and Ridolfo, in the press). At a daily dosage level of $6 \mathrm{mg}$., the compound promoted little or no increase in urinary excretion of nitrogen, phosphorus, and calcium; but at higher doses, such as $15 \mathrm{mg}$., it exerted definite catabolic effects.

In December, 1959, we undertook a clinical appraisal of paramethasone. From direct comparison studies in twelve patients, its antirheumatic strength was estimated as $2 \cdot 8$ times greater than that of prednisolone, indicating that 16-methylation increased the potency of fluprednisolone only slightly. Our long-term treatment studies with paramethasone are still in progress. They embrace a total of 82 rheumatoid patients, 64 of whom have now been observed for longer than 10 months. Ten patients who had never before received steroid therapy were given initial doses of 4 to $7 \mathrm{mg}$. a day. The pattern of their early response followed that produced by other active anti-inflammatory analogues. In 62 patients, therapy was transferred from another steroid-from prednisolone in 32, from dexamethasone in six, and from fluprednisolone in 24. In twenty of the prednisolone-treated patients, the improvement had been graded as inadequate, but with paramethasone six of them recovered their previous status. Thus, as with other compounds, a change of medication to paramethasone will sometimes better the condition of patients whose rheumatic manifestations have escaped control.

An analysis of results after 9 months of continuous therapy indicates that the therapeutic efficiency of paramethasone does not differ greatly from that of fluprednisolone. Direct comparative studies suggest that paramethasone may have a somewhat greater tendency than fluprednisolone to cause such unwanted reactions as weight gain, abdominal girth, and distension; since the two drugs differ chemically in only one respect, the development of these side-effects must be influenced by 16-methylation.

\section{Summary}

Our experience with eight antirheumatic corticosteroid compounds has shown that none of them approximates to our ideal of a suppressive agent for rheumatoid arthritis and other steroid-responsive conditions. Some of the analogues exhibit qualitative differences in one or another physiological action, but the major deterrent features of corticosteroids are shared by each of them. Prednisone, prednisolone, methylprednisolone, fluprednisolone, and paramethasone seem to have similar therapeutic indices; and there appears to be little to choose between them for the ordinary patient who requires steroid therapy. Conversely, because they produce unique reactions of their own and because they have greater proclivity to certain troublesome sideeffects, the therapeutic indices of dexamethasone, betamethasone, and triamcinolone are lower than that of prednisolone; they are less desirable for routine use and are best employed for selected cases as "special purpose" steroids.

This study was supported, in part, by a grant from the Ahmanson Foundation.

Grateful acknowledgement is made to the following pharmaceutical companies for supply of steroids: to Merck Sharp and Dohme Inc., West Point, Pa., for prednisone, prednisolone, dexamethasone, and betamethasone; to the Upjohn Co., Kalamazoo, Mich., for methylprednisolone and fluprednisolone; to Lederle Laboratories, Pearl River, N.Y., for triamcinolone; and to the Eli Lilly Co., Indianapolis, Ind., for paramethasone. 


\section{REFERENCES}

Arth, G. E., Fried, J., Johnston, D. B. R., Hoff, D. R., Sarett, L. H., Silber, R. H., Stoerk, H. C., and Winter, C. A. (1958). J. Amer. chem. Soc., 80, 3161.

- -, Johnston, D. B. R., Fried, J., Spooncer, W. W., Hoff, D. R., and Sarett, L. H. (1958). Ibid., 80, 3160 .

Bernstein, S., Lenhard, R. H., Allen, W. S., Heller, M., Littell, R., Stolar, S. M., Feldman, L. I., and Blank, R. H. (1956). Ihid., 78, 5693.

Boland, E. W. (1952). Brit. med. J., 1, 559.

- (1955). Ann. N.Y. Acad. Sci., 61, 591.

(1956). J. Amer. med. Ass., 160, 613.

(1957). Med. Clin. N. Amer., 41, 553.

(1958a). In "Progress in Arthritis", ed. J. H. Talbott and L. M. Lockie, pp. 130-53. Grune and Stratton, New York.

(1958b). Calif. Med., 88, 417.

(1958c). Ann. rheum. Dis., 17, 376.

(1959). Ann. N.Y. Acad. Med., 82, 887.

(1960). J. Amer. med. Ass., 174, 835.

(1961a). Amer. J. Med., 31, 581.

(1961b). "Proc. X Int. Congr. Rheum. Dis.", vol. 1, p. 355. Rome.

and Headley, N. E. (1952). J. Amer. med. Ass., 148, 981.

(1954). Ann. rheum. Dis., 13, 291.

(1958). Calif. Med., 89, 262.

and Liddle, G. W. (1957). Ann. rheum. Dis., 16, 279.

Borman, A., and Singer, F. M. (1954). Fed. Proc., 13, 185.

, and Numerof, P. (1954). Proc. Soc. Exp. Biol. (N.Y.), 86, 570.

Bowers, A. (1959). J. Amer. chem. Soc., 81, 4107.

-.. and Ringold, H. J. (1958). Ibid., 80, 4423.

Bunim, J. J., Black, R. L., Lutwak, L., Peterson, R. E., and Whedon, G. D. (1958). Arthr. and Rheum., 1, 313.

—-, Pechet, M. M., and Bollet, A. I. (1955). J. Amer. med. Ass., 157, 311.

Edwards, J. A., Ringold, H. J., and Djerassi, C. (1960). J. Amer. chem. Soc., 82, 2318.

Frawley, T. F., Kistler, H., and Shelley, T. (1959). N. Y. Acad. Sci., 82, 868.

Freyberg, R. H., Berntsen, C. A., Jr., and Hellman, L. (1958). Arthr. and Rheum., 1, 215.

Fried, J., and Sabo, E. F. (1953). J. Amer. chem. Soc., $75,2273$.

- - (1954). Ibid., 76, 1455.

Hench, P. S., Kendall, F. C., Slocumb, C. H., and Polley, H. F. (1950). Arch. intern. Med., 85, 545.

-- and Ward, L. E. (1954). In "Medical Uses of Cortisone", pp. 177, ed. F. D. W. Lukens. Blakiston New York.
Herzog, H. L., Nobile, A., Tolksdorf, S., Charney, W., 므 Hershberg, E. B., Perlman, P. L., and Pechet, M. M. (1955). Science, 121, 176.

Hogg, J. A., Lincoln, F. H., Jackson, R. W., and蛋 Schneider, W. P. (1955). J. Amer. chem. Soc.믕 77, 6401 .

—, Spero, G. B., Thompson, J. L., Magerlein, B. J. Schneider, W. P., Peterson, D. H., Sebek, O. K. $\stackrel{\mathbb{Q}}{\square}$ Murray, H. C., Babcock, J. C., Pederson, R. L. and Campbell, J. A. (1958). Chem. and Ind. (Lond.), 77, 1002.

Ingle, D. J., and Kuizenga, M. H. (1945). Endocrinology 36, 218.

Irwin, G. W., and Ridolfo, A. S. (Data to be published.) Kammerer, W. H. (1961). In "Proc. I Conf. Clin 응 Appl. Betamethasone". Schering.

Oliveto, E. P. (1959). Ann. N.Y. Acad. Sci., 82, 809. i

Pabst, M. L., Sheppard, R., and Kuizenga, M. H. (1947) Endocrinology, 41, 55.

Silber, R. H. (1959). Ann. N.Y. Acad. Sci., 82, 821. 을 Spero, G. B., Thompson, J. L., Magerlein, B. J., Hanze, A. R., Murray, H. C., Sebek, O. K., and Hegg J. A. (1956). J. Amer. chem. Soc., 79, 6213.

Thorn, G. W. (1950). In "Proc. I Clin. ACTH Conf." $\vec{c}$ ed. J. R. Mote, p. 176. Blakiston, Philadelphia

West, K. M., Johnson, P. C., Kyriakopoulos, A. A.? Bahr, W. J., and Bloedow, C. E. (1960). Aithr. and Rheum., 3, 129.

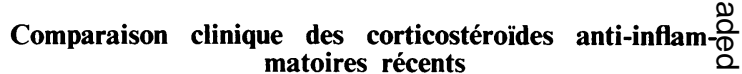

\section{RÉSUMÉ}

Notre expérience avec huit composés corticostéroïdesantirhumatismaux a montré qu'aucun d'entre eux ne् s'approche de notre idéal comme agent de suppression. dans l'arthrite rhumatismale ou dans d'autres affectionso sensibles aux stéroïdes. Certains analogues de la cortisone manifestent des différences qualitatives dansoses actions psychologiques, mais la plupart des traits 3 . décourageants sont communs à tous. La prednisone, prednisolone, methylprednisolone, fluorprednisolone et? paramethasone semblent avoir des indices thérapeutiques similaires et pour le malade ordinaire ayant besoin d'un? treatement stéroïde le choix importe peu. Par contre, en raison de leurs réactions spécifiques et de certainso effets secondaires nuisibles, les indices thérapeutiques de la dexamethasone, bétamethasone et triamcinolonen sont inférieurs à ceux de la prednisolone; pour cette raison leur emploi courant est peu désirable et il est $N$ préférable de les réserver pour des cas particuliers commeñ "stéroïdes pour usage spécial".

Comparación clínica de los modernos corticosteroides

\section{Sumario}

Nuestra experiencia con ocho compuestos cortico- 0 steroides antirreumáticos ha mostrado que ninguno de ellos se aproxima a nuestro ideal de un agente supresivo $\frac{\vec{\Phi}}{\vec{D}}$ para la artritis reumatoide y otras condiciones sensiblese a esteroides. Algunos análogos de la cortisona muestrano 
diferencias cualitativas en una u otra acción psicológica, pero los mayores rasgos repulsivos son compartidos por cada uno de ellos. Prednisona, prednisolona, metilprednisolona, fluorprednisolona y parametasona aparentan tener indicios terapéuticos similares y para el paciente ordinario que requiere terapéutica esteroide poco importa el cual de ellos se escoge. Contrariamente, porque producen reacciones especificas y porque tienen una mayor tendencia a ciertos molestos efectos secundarios, los indicios terapéuticos de la dexametasona, betametasona y triamcinolona son menores que los de la prednisolona; por esta razón son menos deseables para el uso corriente, prefiriéndose su empleo para casos seleccionados como "esteroides de efecto especial". 